\title{
Children's interaction with the Internet: Time dedicated to communications and games
}

\author{
José Alberto Molina* \\ University of Zaragoza, Spain \\ IZA, Germany \\ Juan Carlos Campaña \\ University of Zaragoza, Spain \\ Raquel Ortega \\ University of Zaragoza, Spain
}

\begin{abstract}
In the context of growing interest of individuals on the Internet, the literature has not paid attention to the uses of time for children, given the scarcity of appropriate data bases that provide accurate information. To partially cover this gap, we now provide here evidence of the time that children aged between 10 and 12 years old dedicate to two online activities: computer communication and computer gaming. To that end, we estimate a simultaneous SUR model with data from the Spanish Time Use Survey for 2009-2010. Results indicate that being female generates a positive influence on the time devoted to computer communication, and being male generates a positive influence on the time devoted to computer gaming. We also find that a greater number of family members with secondary studies generates a positive influence on the time spent on computer gaming. Children with better health spend more time on both of these activities and, finally, living in a larger city produces a positive effect on the time dedicated to computer gaming.
\end{abstract}

Keywords: Children, Internet, Leisure time, SUR Model

JEL Classification: D12, J13, J22

\footnotetext{
* Corresponding author. J.A. Molina. Email: jamolina@unizar.es. Telephone: 349767618 18. Fax: 34976761996. Web: http://dae.unizar.es/jamolina/
} 


\section{I.Introduction}

In this paper, we study the determinants of the time that children between the ages of 10 and 12 (inclusive), in Spain, spend on two internet activities: computer communication and computer gaming. With millions using the Internet every day around the world, it is essential to recognize the dramatic growth of online relationships, specifically between consumption and the Internet. Specifically, children and youths are becoming particularly active and heavy Internet users with greater access to the Internet than most other population segments. Technology and the media have become a significant part of this young consumer group's lifestyle. Thus, Lichy (2011) surveys teenage school students (aged 13-15) in order to compare Internet user behavior across urban and suburban areas in north-west England and south-east France, finding that French and British teenagers behave very similarly online. This study supports the notion of converging Internet use across national borders, although there do appear signs of an urban-suburban disparity in the use of the Internet for educational purposes.

In this context of growing interest of consumers with respect to online options, the literature on consumption of internet goods includes, primarily, e-shopping analyses by age and other socio-demographic variables, with the evidence providing results for adolescents, young people, or the elderly, but the literature has not paid attention to the uses of time for children aged under 12. This is understandable, given the scarcity of appropriate data bases that provide accurate information about these consumers.

In the context of the increasing number of consumers who use the Internet to purchase products and services, Seock and Chen-Yu (2007) identify five online consumer shopping orientations for college students (aged 18-22) at two US universities, one in the East and one in the Mid-West. The authors focus on apparel websites because clothing constitutes one of the top categories of merchandise sold online, finding that, among the five criteria, privacy/security received the highest mean score in all situations for all purchaser groups. In this line, Seock and Bailey (2008) use college students (aged 18-22) at two Eastern US universities to specifically check gender differences in shopping orientations. Results show that female students had greater shopping enjoyment, brand/fashion consciousness, price consciousness, and shopping confidence than male participants, in this way indicating that female students tend to seek hedonic benefits, such as excitement, in their online shopping. 
Finally, Batat (2008) explores the consumption skills of French 11-15 year old consumers using the new technologies. The author uses qualitative data to illustrate a specific group of teenagers' consumption of digital products within their leisure activities. Results first indicate that teenagers are active participants in, and producers of, their own cultural consumption processes. Additionally, teenagers' perceptions of the competence necessary to consume lies first and foremost in skills associated with preventive behaviours, good management of their pocket money, and the wise use of the Internet and blogs to experience a better consumption process.

Other papers have analyzed different age groups, with Eastman and Iyer (2005) and Fowler et al. (2015) focusing on various uses of the internet for the elderly. In the context of older consumers comprising a growing segment of Internet users, Eastman and Iyer (2005) discuss the impact of the cognitive age of American consumers 65 years old or older, on their Internet use, with results indicating that seniors with lower cognitive age will use the Internet more than seniors who are older in cognitive age. Fowler et al. (2015) investigate the strategies that consumers deploy to cope with ageing issues through internet communications.

Regarding other socio-demographic variables, certain papers have focused on the effects of gender and other demographic variables on online shopping behavior. Hui and Wan (2007) examine the influence of gender and educational issues on online shopping behavior in Singapore, finding no significant differences between males and females with respect to security concerns, and with better-educated respondents appearing to be less concerned with security issues. Jacobs and de Klerk (2010) explore the role that existing apparel shopping scripts play in female consumers' adoption of the Internet for online apparel purchasing in South Africa. Finally, Wu et al. (2011) investigate Chinese consumers' personal value orientations and their Internet usage, in terms of online shopping behaviour.

Against this background, it is clear that the Internet has become part of the daily life of youth today and that children and youth consumers use the Internet as a medium to browse and explore issues of interest, with communications with others and playing games being two fundamental aspects of their entertainment activities. In this context, we analyze the time that children aged 10-12 spend on two online activities: computer communication and computer gaming. We estimate a SUR model with data from the 
Spanish Time Use Survey for 2009-2010. ${ }^{1}$ Our simultaneous model of time use depends on demographic, educational, and family variables, thus bridging the gap in the literature of consumption that has omitted the determinants of the time that children dedicate to online activities.

\section{II.Data and Variables}

This study uses data from the Spanish Time Use Survey from the fourth quarter of 2009 to the third quarter of 2010, inclusive. Those interviewed are all family members 10 years of age or older. Each respondent fills in a diary for a specific day of the week, indicating what activities were done during the course of the day, at intervals of 10 minutes (144 intervals in total). An extensive literature confirms the validity and reliability of data from diaries and its advantages over other time-use surveys based on simple questions, in which those being surveyed are asked to estimate the time dedicated to a certain activity on a "typical day", or during a "typical week"; for example, the hours that respondent worked the day or week before (Robinson and Godbey, 1999; Bianchi et al, 2000; Kalenkoski and Pabilonia, 2012). Furthermore, Time-use surveys provide individual information and are the typical instrument used to analyse time-allocation decisions (Aguiar and Hurst, 2007; Giménez-Nadal and Sevilla, 2012). We restricted our sample to those individuals who are between the ages of 10 and 12 (inclusive), and we focus on analyzing the time spent on two activities: computer communication and computer gaming. ${ }^{2}$

For the variables that could influence whether those being surveyed dedicate more or less time to these two activities, we use age and age squared divided by 100 (Kalenkoski et al, 2005; Aguiar and Hurst, 2007; Gimenez-Nadal., et al 2011), along with gender, which is important in that free-time preferences vary with gender (Gimenez- Nadal and Sevilla, 2012). We also consider whether both parents live in the home, and the education levels of household members in three levels of education: Primary education (less than a secondary school diploma), Secondary education (a secondary school diploma) and University education (more than a secondary school

\footnotetext{
${ }^{1}$ The SUR model has been used to describe the simultaneity of consumption goods (see, for example, for the case of Spain, Molina et al. 2015, 2016, for cultural goods)

${ }^{2}$ Computer communication refers to time dedicated to reading, writing and sending emails; chat via the internet; other computer communications such as videoconferencing. Informatics games refers to time dedicate to video games, computer games and mobile phone games.
} 
diploma). ${ }^{3}$ Education influences the distribution of time that individuals allocate to different activities (Kalenkoski et al., 2005; Guryan et al., 2008), so we want to know whether the level of education of household members influences the time devoted by our sample in the analyzed activities.

Studies such as Gimenez-Nadal and Molina (2015) show that an individual's good health can lead to the dedication of more time to market work and less time to leisure activities, so we control for the state of health of the individual (self-reported) with five levels ( 1 =very good health, to $5=$ very poor health). We also consider the size of the municipality where the respondents live, with five classifications: municipality with a population greater than 100,000 , municipality with a population between 50,000 and 100,000, municipality with a population between 20,000 and 50,000, municipality with a population between 10,000 and 20,000, and municipality with a population less than 10,000. The size of the municipality can influence the time spent by individuals in different activities (Molina et al., 2015).

(Table 1)

Table 1 shows the descriptive statistics for the average time spent on a daily basis, on computer communication and computer gaming, along with the descriptive statistics for our socio-demographic variables. Column 1 for males, Column 2 for females, and Column 3 for the whole sample. We can see that girls devote more time to computer communication ( 0.18 hours per day) compared to boys ( 0.06 hours per day), while boys devote more time to gaming ( 0.67 hours per day) compared to girls $(0.24$ hours per day). The average age for our sample is 11 years (considering that our sample is restricted to individuals between the age of 10 and 12). In $83 \%$ of households, both parents are living and we see more than four members, on average, in each household. In terms of education levels, we observe that the level of primary education predominates with more than two members per household. As for their state of health, the majority of the boys (62\%) and the girls (68\%) report being in very good health. Furthermore, $51 \%$ of the sample live in a municipality with a population over 100,000.

\section{III.Methodology and Results}

Hamermesh and Lee (2007) argue that time is scarce and people suffer from a lack of sufficient time to carry out all desired activities. In this sense, our analyzed sample will

\footnotetext{
${ }^{3}$ Studies of time use as Gimenez-Nadal and Molina (2013), Gimenez -Nadal and Molina (2014), Campaña., et al (2015) have used this classification.
} 
have to combine their responsibilities (going to school, performing academic duties) with leisure activities. Each individual reports two uses of time and, as in other time-use studies (Gimenez-Nadal and Molina 2013, 2015), a SUR (seemingly unrelated regressions) model is estimated for the time individuals spend in computer communication and computer gaming.

The statistical model is as follows: For an individual " $i$ ", $T_{c i}$ and $T_{g i}$, represent the hours reported by the individuals that are dedicated to computer communication and computer gaming. $\mathrm{X}_{\mathrm{i}}$ is the vector of the characteristics of the household and of the individuals, and $\varepsilon_{\mathrm{ci}}$ and $\varepsilon_{\mathrm{gi}}$, represent the random variables for factors not measured. Thus, we estimate the following two equations

$$
\begin{aligned}
& T_{c i}=\beta \mathrm{X}_{\mathrm{i}}+\varepsilon_{\mathrm{ci}} \\
& T_{g i}=\beta \mathrm{X}_{\mathrm{i}}+\varepsilon_{\mathrm{gi}}
\end{aligned}
$$

Concerning the specification of the error terms for each individual, we permit the correlations of the unobserved determinants of the activities, and the error terms are normally distributed as a whole, without restrictions in the correlation. This specification shows the time limitation that could lead individuals to spend more time on one activity, and less time on another. Moreover, we assume that the error components are independent:

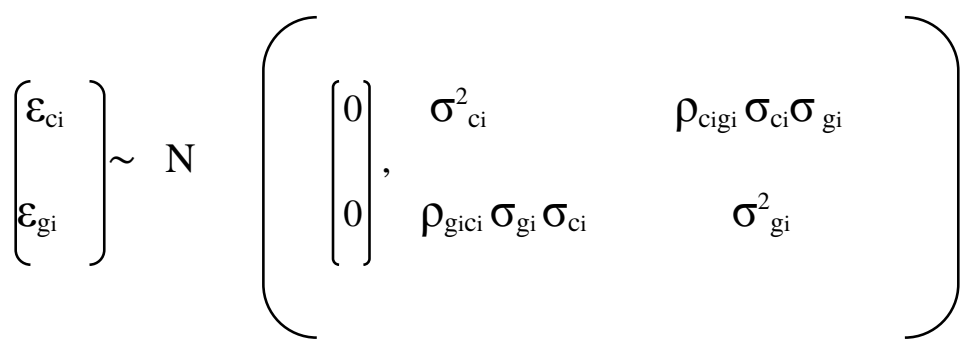

Columns 1 and 2 in Table 2 show the results of our estimations for the time dedicated to communications and gaming. As shown, gender influences the time spent on these two activities, being a girl generates a positive influence on the time devoted to communications and being a boy generates a positive influence on the time devoted to gaming. These gender differences are in accordance with prior evidence from Seock and 
Bailey (2008) which, for the case of online shopping, found significant differences between male and female college students in the US.

In terms of education, we find that the greater the number of family members with secondary studies generates a positive influence on the time spent on gaming. This is related to the presence of older brothers and sisters at home, which positively influences the time that younger children dedicate to online games given the “contagion/imitation” effect. This is also related to the work of Hui and Wan (2007), who find a positive influence of the level of education of the individual on security and increased use of the Internet.

Health status shows a significant influence on the time dedicated to computer communication and computer gaming, in that individuals with better health spend more time on these online activities. We understand here that a good level of health and, consequently, a good state of mind will positively contribute to communication with peers, and to play. With respect to the size of the municipality, we can see significant and positive values for the municipality size 1 (a population greater than 100,000) and municipality size 2 (a population between 50,000 and 100,000) in the time devoted to gaming, with this result being in partial agreement with the findings of Lichy (2011) who confirms the existence of urban-suburban disparities for French and British adolescents in certain specific uses of the Internet.

\section{IV.Conclusions}

It is clear that parents and educators should educate children in the consumption and use of new technologies and policy-makers must bear in mind the need to act accordingly to protect the vulnerable children segment. In this context, we here provide evidence of the time that children aged 10-12 years old dedicate to two online activities: computer communication and computer gaming. To that end, we estimate a simultaneous SUR model with data from the Spanish Time Use Survey for 2009-2010.

Our results indicate that being a girl generates a positive influence on the time devoted to communications while being a boy generates a positive influence on the time devoted to computer gaming. We also find that the greater the number of family members with secondary studies, that is to say, the habitual presence of older brothers and sisters, generates a positive influence on the time spent on gaming. Children with better health exhibit higher levels of intelligence and, consequently, spend more time in 
communications and gaming activities, and living in larger cities produces an urban positive effect on the time specifically dedicated to computer gaming.

It is a fact that the Internet has become an integral part of the daily life of children and youth today, and the World Wide Web has attracted and continues to attract more and more young people. The general debate on the use and limitations of the Internet to ensure the appropriate levels of privacy and/or security, particularly with respect to this younger segment of the population, has given rise to certain generallyaccepted concerns. The first step is obviously to ensure the parental control of children in the use of online applications at home, and similarly with respect to educators at school. Additionally, and given the scarcity of evidence on the use of the Internet by children, it is timely to provide new rigorous statistical information, to add to the international evidence that contributes to clarify the nature of children's interactions with the Internet.

\section{Disclosure statement}

No potential conflict of interest was reported by the authors.

\section{Funding}

Financial support from the Spanish Ministry of Economics (Project ECO2012-34828) is gratefully acknowledged.

\section{References}

Aguiar, M. and E. Hurst. 2007. "Measuring trends in leisure: the allocation of time over five decades.” Quarterly Journal of Economics 115: 969-1006.

Batat, W. 2008. "Exploring adolescent development skills through Internet usage: a study of French 11-15 years olds.” International Journal of Consumer Studies 32: 374-381.

Bianchi, S. M., M.A. Milkie, L.C. Sayer, and J.P. Robinson. 2000. “Is anyone doing the housework? Trends in the gender dividion of household labor.” Social Forces 79: 191-228.

Campaña, J., J.I. Giménez-Nadal, and J.A. Molina. 2015. "Gender differences in the distribution of total work-time of Latin-American families: the importance of social norms.” IZA DP No. 8933. 
Eastman, J.K. and R. Iyer. 2005. "The impact of cognitive age on the Internet use of the elderly: an introduction to the public policy implications.” International Journal of Consumer Studies 29: 125-136.

Fowler, J.G., J.W. Gentry and T.H. Reisenwitz. 2015. “Analyzing Chinese older people's quality of life through their use of the internet.” International Journal of Consumer Studies 39: 324-334.

Gimenez-Nadal, J. I. and J.A. Molina. 2013. “Parents' education as a determinant of educational childcare time.” Journal of Population Economics 26: 719-749.

Gimenez-Nadal, J. I. and J.A. Molina. 2014. "Regional unemployment, gender and time allocation of the unemployed.” Review of Economics of the Household 12: 105-127.

Gimenez-Nadal, J. I. and J.A. Molina. 2015. "Health status and the allocation of time: Cross-country evidence from Europe.” Economic Modelling 46: 188-203.

Gimenez-Nadal, J. I. and A. Sevilla. 2012. “Trends in time allocation: a cross-country analysis.” European Economic Review 56: 1338-59.

Gimenez-Nadal, J. I., J.A. Molina, and R. Ortega. 2011. "Self-employed mothers and the work-family conflict.” Applied Economics 44: 2133-2147.

Guryan, J., E. Hurst and M. Kearney. 2008. "Parental education and parental time with children.” Journal of Economic Perspectives 22: 23-46.

Hamermesh, D. S. and J. Lee. 2007. "Stressed out on four continents: Time crunch or yuppie kvetch?” The Review of Economics and Statistics 89: 374-383.

Hui, T-K. and D. Wan. 2007. "Factors affecting Internet shopping behavior in Singapore: gender and educational issues.” International Journal of Consumer Studies 31: 310-316.

Jacobs, B. and H. de Klerk, H. 2010. “Online apparel shopping behavior of South African professional women: the role of consumers' apparel shopping scripts.” International Journal of Consumer Studies 34: 255-264.

Kalenkoski, C. M. and S.W. Pabilonia. 2012. “Time to work or time to play: the effect of student employment on homework, sleep, and screen time.” Labour Economics, 19: $211-21$.

Kalenkoski, C., D. Ribar, and L. Stratton. 2005. "Parental child care in single parent, cohabiting, and married couple families: time diary evidence from the United Kingdom.” American Economic Review: Papers and Proceedings 95: 194-8. 
Lichy, J. 2011. “Internet user behavior in France and Britain: exploring sociospatial disparity among adolescents.” International Journal of Consumer Studies, 35: 470-475.

Molina, J.A., J.C. Campaña, and R. Ortega. 2015. “Time dedicated by consumers to cultural goods: determinants for Spain.” MPRA WP 68430.

Molina, J.A., J.C. Campaña, and R. Ortega. 2016. “Time spent on cultural activities at home in Spain: Differences between wage-earners and the self-employed.” Documento de Trabajo. Facultad de Economía y Empresa. Universidad de Zaragoza. DTECONZ 2016-01.

Robinson, J. P. and G. Godbey. 1999. “Time for Life: The Surprising Ways Americans Use Their Time.” Pennsylvania State University Press, University Park, PA

Seock, Y-K. and L.R. Bailey. 2008. “The influence of college students' shopping orientations and gender differences on online information searches and purchase behaviours.” International Journal of Consumer Studies 32: 113-121.

Seock, Y-K. and J.H. Chen-Yu. 2007. "Website evaluation criteria among US college student consumers with different shopping orientations and Internet channel usage.” International Journal of Consumer Studies 31: 204-212.

Wu, L., Y. Cai, and D. Liu. 2011. “Online shopping among Chinese consumers: an exploratory investigation of demographics and value orientation.” International Journal of Consumer Studies 35: 458-469. 
Table 1. Descriptive Statistics

\begin{tabular}{|c|c|c|c|c|c|c|}
\hline \multirow[b]{2}{*}{ Variables } & \multicolumn{2}{|c|}{ Male } & \multicolumn{2}{|c|}{ Female } & \multicolumn{2}{|c|}{ Total } \\
\hline & Average & SD & Average & SD & Average & SD \\
\hline Computer communication (daily hours) & 0.06 & $(0.403)$ & 0.18 & $(0.567)$ & 0.12 & $(0.49)$ \\
\hline Informatics games (daily hours) & 0.67 & $(1.295)$ & 0.24 & $(0.861)$ & 0.47 & $(1.13)$ \\
\hline Age & 11.01 & $(0.802)$ & 11.03 & $(0.792)$ & 11.02 & $(0.80)$ \\
\hline Households with both spouses & 0.84 & $(0.368)$ & 0.82 & $(0.388)$ & 0.83 & $(0.38)$ \\
\hline N. household members & 4.24 & $(1.105)$ & 4.12 & $(1.089)$ & 4.18 & $(1.10)$ \\
\hline N. household members with Primary education & 2.45 & $(1.218)$ & 2.28 & $(1.206)$ & 2.37 & $(1.21)$ \\
\hline N. household members with Secondary education & 0.54 & $(0.736)$ & 0.70 & $(0.766)$ & 0.62 & $(0.75)$ \\
\hline N. household members with University education & 0.47 & $(0.736)$ & 0.44 & $(0.700)$ & 0.45 & $(0.72)$ \\
\hline Very good health & 0.62 & $(0.487)$ & 0.68 & $(0.466)$ & 0.65 & $(0.48)$ \\
\hline Good health & 0.37 & $(0.484)$ & 0.30 & $(0.459)$ & 0.34 & $(0.47)$ \\
\hline Acceptable health & 0.01 & $(0.086)$ & 0.01 & $(0.111)$ & 0.01 & $(0.10)$ \\
\hline Poor health & 0.004 & $(0.061)$ & 0.004 & $(0.065)$ & 0.004 & $(0.06)$ \\
\hline Very poor health & 0.004 & $(0.061)$ & 0.000 & $(0.000)$ & 0.002 & $(0.04)$ \\
\hline Municipality size 1 & 0.51 & $(0.501)$ & 0.52 & $(0.501)$ & 0.51 & $(0.50)$ \\
\hline Municipality size 2 & 0.11 & $(0.316)$ & 0.11 & $(0.317)$ & 0.11 & $(0.32)$ \\
\hline Municipality size 3 & 0.11 & $(0.311)$ & 0.10 & $(0.301)$ & 0.10 & $(0.31)$ \\
\hline Municipality size 4 & 0.09 & $(0.281)$ & 0.06 & $(0.243)$ & 0.07 & $(0.26)$ \\
\hline Municipality size 5 & 0.18 & $(0.387)$ & 0.21 & $(0.407)$ & 0.19 & $(0.40)$ \\
\hline Observations & 26 & 68 & 24 & 40 & 50 & 88 \\
\hline $\begin{array}{l}\text { Note: Standard deviations in parentheses. Data from t } \\
\text { between the ages of } 10 \text { and } 12 \text {. Primary education is e } \\
\text { education is equivalent to having a secondary school } \\
\text { secondary school diploma. Municipality size } 1 \text { is eq } \\
\text { municipality size } 2 \text { is equivalent to a municipality wi } \\
\text { equivalent to a municipality with a population between } \\
\text { with a population between } 10,000 \text { and } 20,000 \text {, and mur } \\
\text { than } 10,000 \text {. }\end{array}$ & a. & $\begin{array}{l}\text { sity e } \\
\text { Inicip } \\
\text { etwe }\end{array}$ & $\begin{array}{l}n \text { is } \\
\text { ith }\end{array}$ & $\begin{array}{l}\text { ivalen } \\
\text { inatio } \\
100,00 \\
\text { is equ }\end{array}$ & 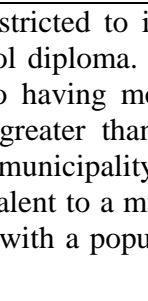 & $\begin{array}{l}\text { ore th } \\
\text { n } 100 \text {, } y \text { size }\end{array}$ \\
\hline
\end{tabular}


Table 2. Estimations of the SUR model

\begin{tabular}{|c|c|c|}
\hline \multirow[b]{2}{*}{ Variables } & \multirow{2}{*}{$\begin{array}{c}\begin{array}{c}\text { Computer } \\
\text { communication }\end{array} \\
(1)\end{array}$} & \multirow{2}{*}{$\begin{array}{c}\text { Informatics games } \\
(2)\end{array}$} \\
\hline & & \\
\hline \multirow[t]{2}{*}{ Male } & $-0.101 * *$ & $0.445^{* * *}$ \\
\hline & $(0.0439)$ & $(0.0969)$ \\
\hline \multirow[t]{2}{*}{ Age } & -0.177 & -3.034 \\
\hline & $(0.930)$ & $(2.366)$ \\
\hline \multirow[t]{2}{*}{ Age squared } & 1.207 & 13.45 \\
\hline & $(4.272)$ & $(10.68)$ \\
\hline \multirow{2}{*}{ Household with both spouses } & -0.0349 & -0.213 \\
\hline & $(0.0629)$ & $(0.178)$ \\
\hline \multirow{2}{*}{ N. household members with Primary education } & -0.0229 & 0.0716 \\
\hline & $(0.0246)$ & $(0.0562)$ \\
\hline \multirow{2}{*}{ N. household members with Secondary education } & -0.00479 & $0.158 *$ \\
\hline & $(0.0391)$ & $(0.0950)$ \\
\hline \multirow[t]{2}{*}{ N. household members with University education } & -0.0486 & -0.0470 \\
\hline & $(0.0383)$ & $(0.0710)$ \\
\hline \multirow[t]{2}{*}{ Very good health } & $0.230 * *$ & $0.968 * * *$ \\
\hline & $(0.0962)$ & $(0.231)$ \\
\hline \multirow[t]{2}{*}{ Good health } & $0.202 * * *$ & $0.789 * * *$ \\
\hline & $(0.0693)$ & $(0.223)$ \\
\hline \multirow[t]{2}{*}{ Acceptable health } & 0.0806 & $0.790 * * *$ \\
\hline & $(0.109)$ & $(0.280)$ \\
\hline \multirow[t]{2}{*}{ Bad health } & 0.0625 & $0.538^{*}$ \\
\hline & $(0.101)$ & $(0.326)$ \\
\hline \multirow[t]{2}{*}{ Municipality size 1} & -0.00805 & $0.226 * *$ \\
\hline & $(0.0616)$ & (0.0987) \\
\hline \multirow[t]{2}{*}{ Municipality size 2} & 0.0774 & $0.556 * *$ \\
\hline & $(0.0963)$ & $(0.258)$ \\
\hline \multirow[t]{2}{*}{ Municipality size 3} & -0.0291 & 0.208 \\
\hline & $(0.0845)$ & $(0.141)$ \\
\hline \multirow[t]{2}{*}{ Municipality size 4} & -0.0100 & 0.140 \\
\hline & $(0.0750)$ & $(0.157)$ \\
\hline \multirow[t]{2}{*}{ Constant } & 0.583 & 16.13 \\
\hline & (5.074) & (12.86) \\
\hline R-squared & 0.054 & 0.095 \\
\hline Observations & 508 & 508 \\
\hline
\end{tabular}

Note: Robust standard errors in parentheses. Data from the Spanish TUS 2009-2010. The sample is restricted to individuals between the ages of 10 and 12. Primary education is equivalent to having less than a secondary school diploma. Secondary education is equivalent to having a secondary school diploma. University education is equivalent to having more than a secondary school diploma. Municipality size 1 is equivalent to a municipality with a population greater than 100,000 , municipality size 2 is equivalent to a municipality with a population between 50,000 and 100,000, municipality size 3 is equivalent to a municipality with a population between 20,000 and 50,000 , municipality size 4 is equivalent to a municipality with a population between 10,000 and 20,000, and municipality size 5 is equivalent to a municipality with a population less than 10,000 . Sunday taken as a reference day. * Significant at $90 \%$. ** Significant at $95 \%$. *** Significant at $99 \%$. 